\title{
The Attitude of Sudanese EFL Students towards Literature to Enrich Their Vocabulary Building
}

\author{
Abbas Hussein Abdelrady $\mathbb{D D}^{1},{ }^{1}$ Syed Farhat Jahara $\mathbb{C D}^{1},{ }^{1}$ Azza Elmadani Adam Elmadani $\mathbb{D}^{\circ},{ }^{2}$ \\ and Tribhuwan Kumar (D) $^{3}$ \\ ${ }^{1}$ Department of English Language and Translation, College of Sciences and Arts at Al-Asyah, Qassim University, Buraydah, \\ Saudi Arabia \\ ${ }^{2}$ Department of English Language, School of Languages, Ahfad University for Women, Omdurman, Sudan \\ ${ }^{3}$ College of Science and Humanities at Sulail, Prince Sattam Bin Abdulaziz University, Al Kharj 11942, Saudi Arabia
}

Correspondence should be addressed to Tribhuwan Kumar; t.kumar@psau.edu.sa

Received 23 October 2021; Accepted 6 January 2022; Published 28 January 2022

Academic Editor: Ehsan Namaziandost

Copyright (C) 2022 Abbas Hussein Abdelrady et al. This is an open access article distributed under the Creative Commons Attribution License, which permits unrestricted use, distribution, and reproduction in any medium, provided the original work is properly cited.

\begin{abstract}
This study aims to explain the attitude and perception of Sudanese EFL secondary school students towards learning literature to enrich their vocabulary. The study is unique as the researchers believe that no significant research in the undertaken area has been conducted in secondary schools in Sudan. The study sample consists of seventy-nine subjects: thirty girls, thirty-five boys, and fourteen teachers from Ahfad Secondary School in Khartoum. This study investigated vocabulary acquisition challenges faced by secondary school students of Ahfad due to lack of interest, lack of good study material for literature, lack of experienced and wellqualified teachers, lack of modern techniques in the EFL classroom, and the implementation of a designed curriculum. Secondary students can engage in meaningful active communication in English if they have good vocabulary, and literature is the most effective way to expand vocabulary. The study adopted qualitative methodology using a questionnaire and vocabulary building activities to perceive how literature helps vocabulary acquisition. The study results showed that the EFL subjects positively enriched their vocabulary through the existing curriculum. EFL teachers should use innovative methods to inculcate vocabulary acquisition in the heart of the EFL students to develop the spirit of reading sections.
\end{abstract}

\section{Introduction}

Literature is novels, short stories, poems, and plays that most secondary school EFL students wish to read as part of their curriculum or self-interest to improve their vocabulary and language skills. The idea that literature can be considered an integrated component in the FL curriculum has been around for several decades [1]. Vocabulary is a core component of language proficiency. It is a never-ending process. Learning words is a lifelong process, and EFL students should constantly update their vocabulary to achieve language proficiency. There is no fixed method to enhance vocabulary in a day or two. Its acquisition demands meticulous and step-by-step learning. It can be enriched gradually, and one should always evince enthusiasm in finding, education, and understanding new words.
English language teachers, nowadays, use more communicative teaching approaches. This new perspective encourages students to be more self-aware and attentive to their learning process and think logically and critically about it. As a result, many EFL/ESL teachers, educators, and scholars have expressed interest in including literature in the ELT curriculum $[2,3]$. It is true that "literature should be taught at early stages and not only at the eleventh and twelfth grades to familiarize pupils with the literature component and its vital importance to English" [4]. Furthermore, Herr described literature as "an integral and revitalized part of foreign language education at every level" [5]. EFL teaching in Khartoum's secondary schools needs more than grammar forms. It is essential to recognize the material that helps EFL students learn English. Paran stated that literature affects the 
learner's attitude towards the EFL contexts, which students will later read in the future [6]. A great deal of language learning difficulties surfaces in our EFL classrooms. These difficulties can emerge in reading, writing, processing, and retaining information and thus affect both receptive and expressive language to enrich vocabulary. Language skills enable learners to express their feelings, ideas, information, and so on $[7,8]$. It is a tool through which knowledge is acquired and preserved. Students' intercultural awareness can be increased by introducing literature (novels and short stories), fostering empathy, open-mindedness to diversity, and emotional intelligence in students. Vocabulary learning from literature is a great way to improve students' word power.

According to Reed and Levis, language is regularly expressed and conceived in various systems. Learners need to pronounce the sound system's speech units clearly and correctly [9]. In general, these units of speech can be referred to as vocabulary. The learners should make use of the vocabulary appropriately when they speak. The meaning system is called grammar, which is how the learners use the words to express meaning. EFL learners must master and understand both approaches because they work together interchangeably [10].

English literature must be applied as an obligatory but not optional, particularly to EFL learners at the secondary school level. Literature should be taught from fifth grade at a basic level to familiarize the secondary school students with nature and the norms of literature [11]. The curriculum that has been in use in the secondary schools of Khartoum, Sudan, for the past twenty years is the SPINE series. Sudanese EFL experts wrote the SPINE series with the help of native experts. The curriculum focuses on reading a variety of sections designed throughout the course. A series of activities follow virtually every reading section to explore the English language through "working with words, grammar corner, writing tasks, step by step, spine challenge, questionnaire" and other tasks to be answered by the EFL learners to showcase their competence in reading the text and analyzing the questions [12]. "Things Fall Apart" is an African novel written by the famous Nigerian writer Achebe in 1958s [13]. This novel has been chosen as part of the curriculum with the SPINE series in Ahfad Secondary Schools Khartoum to enrich the student's vocabulary.

1.1. The Significance of the Study. Every study focuses on a specific problem and provides suggestions for resolving it. The significance of this study is determined by the importance of the research problem being addressed. The following is a succinct summary of its significance:

(i) Analyzing the attitude and perception of Sudanese EFL secondary school students towards learning literature to enrich their vocabulary

(ii) Using a literature-based method to help Sudanese EFL secondary school students enhance their vocabulary

\section{Literature Review}

Vocabulary has been defined as the science of knowledge of new words and word meanings [14]. However, this definition is simpler than what vocabulary means for many reasons. To begin, there are two types of words: written and spoken. Words that people recognize and use in speaking and listening are included in the oral vocabulary. Words that individuals recognize and use in writing and reading are included in the written vocabulary. Second, there are two types of word knowledge: productive and receptive. Words that individuals commonly employ when writing or speaking make up productive vocabulary. When humans hear or see words, they usually recognize them as receptive vocabulary. Receptive vocabulary is naturally larger than productive vocabulary.

Furthermore, it could include several words to which people allocate meaning, pronunciation, spelling, definitions, and use in speaking and writing. However, for secondary school teachers, vocabulary usually means the hard words learners find in content areas such as textbooks and literature selections. It has been stated that "literature develops a love of reading and allows students opportunities to read for enjoyment" [15].

\subsection{The Importance of Vocabulary in Reading Sections.} Reading sections, short stories, or texts enriches students' vocabulary; therefore, secondary school learners need to gain productive vocabulary and the strategies to create new words and apply them in classroom activities. It was observed that many secondary school students do not have a good number of everyday vocabulary or fundamental wordlearning strategies in their memory and fail to comprehend the reading sections, short stories, and exploring language in their curriculum [12]. It was observed that some secondary students have deficient reading ability to comprehend reading sections and short stories, which indicates a gesture of prevention and failure, which continues from secondary school level to their high school level. Most learners cannot engage in day-to-day conversations in the English language. They lack confidence in communicating with their teachers and peer group. These students often avoid reading sections because they lack minimum vocabulary, confidence, and knowledge to comprehend what they read. Since most students do not read much, they do not have the opportunity to see and learn new terms. This sets in motion the wellknown "Mathew Effects" application of Mathew, "the rich get richer, and the poor get poorer" [16]." In terms of vocabulary building, successful learners usually read more, become good readers, and learn more new words; unsuccessful readers read less, become wrong readers, and learn fewer words. This exact relationship between vocabulary building and reading comprehension appears clearly. For beginners, signs indicate a connection between learning new words and pronunciation awareness. A young learner with an excellent verbal vocabulary will examine the representation of the component sounds of those words more easily and quickly. 
Furthermore, good vocabulary knowledge aids novices in decoding or mapping spoken sounds to written words. If young learners are familiar with their verbal vocabulary, they can quickly and easily sound out, read, and understand them and realize what they have read. If the learners are unfamiliar with their oral vocabulary, they can read sections and understand the text. As a result, an adequate knowledge of vocabulary links the cognitive processes of comprehension and the phonetic processes at the word level [14].

Students can engage in meaningful active communication in English if they have a good vocabulary. Literature is the most effective way to expand one's vocabulary. Some of the difficulties to both teacher and student may be solved by experiencing in using literature through "novels, short stories, and reading sections" in the classroom and providing sample materials devised to overcome vocabulary problems. The content of school textbooks is often enough of a challenge. Many do not want to understand the words that express that content [17]. No doubt that "The short story as well as a frame of a short fiction developed, and became popular" [18]. Moreover, Boyd says that "language is not formed for humans, it is the most important form of human communication; it is exclusively people and the key to all humans activities. It is a vehicle through which the world can be understood and valued otherwise, without language, humans are isolated and helpless" [19]. Regarding the importance of language, an effective teacher provides many opportunities for oral developmental skills to enrich learners' vocabulary acquisition.

\subsection{Literature and Vocabulary Building. A recent study has} been carried out by Bloemert, Jansen, and van de Grift on literature and vocabulary building. They found a model of Comprehensive Approach to Foreign Language.

Literature learning emerged from the study's research on FL curricula [1]. This language model argues in developing vocabulary skills through studying literature. It also engages with the story and creates pleasure in writing and reading. The culture model focuses on the value of literature as a window to culture by helping students appreciate and understand other cultures. Specifically, the present research study will focus on using novels, short stories, reading sections, and activities for vocabulary building from the designed curriculum “The SPINE Series Pupil's Book 5" [12]. It is observed that early exposure to a new vocabulary item, particularly in a story, can sometimes be sufficient for a young learner to recognize the word later. Another reason is that vocabulary instruction could help secondary school students learn how words relate to complex ideas and concepts in the stories they read. In other words, learning new words can improve comprehension, which can help students link individual words with more significant literature concepts. Reading develops pleasure, interest, and love for literature. It should be provided for developing a child's imagination and creativity, giving them vivid experiences through reading, developing insights into human behavior, and nurturing the student's literary awareness and growth. It is also suggested that teachers know students' hobbies and interests, especially in reading, and help them find appropriate books. It is clear that from the above discussion that curiosity is one of the most important motivators at all levels [20]. Understanding the learner's strengths and weaknesses and slightly altering the teaching methods may help many incompetent EFL speakers move up the erudition curve and improve their vocabulary proficiency [21].

2.3. Vocabulary Building. Words and their meanings are the buildings of literacy development. It is pointed out that the young learners who obtain a significant vocabulary could think deeply, express themselves better, and even learn new skills more rapidly. Neuman says, "The children who know many words have probably read more than children who knew or read fewer words. They say that the more words a child knows, the more words they could recognize when seeing them in print. This is because as children learn to sound out words, they will reach into their store of words to figure out what they mean" [22].

\section{Research Questions}

RQ 1. To what extent does school curriculum affect the teaching of literature and vocabulary building to EFL secondary school students?

RQ 2. Why do students study literature?

RQ 3. What genres do students like to enrich their vocabulary?

RQ 4. To what extent does teaching of literature help in the acquisition of vocabulary among EFL secondary school students?

\section{Methodology}

4.1. Participants. The research study subjects were sixty-five secondary school students of the second year and fourteen teachers. There were thirty girls and thirty-five boys from Ahfad Secondary School, ranging between 14 and 17 from Khartoum state. The fourteen teachers chosen for the research study include twelve teachers belonging to the trained category and two untrained categories ranging between 30 and 50. Four were headteachers with three to eleven years of teaching experience among these fourteen teachers. These seventy-nine subjects were chosen for the present research study since they were teaching and learning literature. It was observed that most of the Ahfad Secondary School students experienced vocabulary acquisition problems.

4.2. Ahfad School Curriculum. In Ahfad, the secondary school of Khartoum state, the curriculum consists of the SPINE series, which the National Comprehensive Strategy recommended for education in 1992. The new curriculum implemented by the Ministry of Education, Sudan, is meant to help the EFL learners interact with their teachers, peer group, and feel proud of its rich heritage, culture, and social values. It was designed to develop listening, speaking, reading, and writing skills through individual, pair, and 
group activities, thereby refining a student's communicative ability regarding everyday matters in EFL [10].

The researchers have focused on the "The SPINE Series Pupil's Book 5" proposed for the second year of secondary school students who desire to acquire the Sudan School Certificate and fit into higher education's global demands. The curriculum includes current issues such as the environment, women's concerns, wildlife in Sudan, and technology, emphasizing developing reading sections and writing compositions. It provides good exposure to the students through a variety of reading passages like "Income Generators," "Life in a Baggara Village," "Women on the Move," "Collective Work in the Nuba Mountains," "Water: More Precious Than Gold," "Mass Media," "Wildlife in Sudan" [12]. The curriculum also emphasizes writing styles and registers with a section of writing activities like "official/ business letters," "personal letters," "questionnaires," "information transfer," "short summary," "step by step," and so on to make it motivating and learner-friendly to EFL secondary school students.

4.3. Design of the Study. The researchers used qualitative and quantitative research methods, and the study was divided into Preliminary Investigation Stage I and Primary Investigation Stage II.

4.3.1. Preliminary Investigation Stage I. In the first stage, a preliminary study will be undertaken to focus on the different factors to be studied and examined concerning the problems of the teaching literature to enrich students' vocabulary. This research aimed to observe the sixty-five secondary school students and fourteen teachers of Ahfad Secondary School and their environment by interacting with them to understand their English language teaching and learning problems and the challenges of vocabulary acquisition. The emphasis is also to understand the subject's ability and perception of vocabulary acquisition through informal talks. To investigate the preliminary investigation stage, one of the researchers observed the subjects for a month to get a clear understanding of their needs.

4.3.2. Primary Investigation Stage II. In the primary investigation stage, a questionnaire with four sections for both teachers and students was administered to acquire their opinion and perceptions of the use of literature in enriching vocabulary and some vocabulary-building activities. The designed questionnaire was administered to collect data of sixty-five boys and girls and fourteen teachers selected as subjects. The questionnaire distributed to students was designed in a simple language for clarity and ease of understanding. It was translated from English to Arabic to make learners feel free to answer. The questionnaires answered by both students and teachers gathered information on teaching and learning experiences of vocabulary acquisition, the effect of school facilities, teacher factor, students interest, and the impact of literature in vocabulary building.
All the subjects completed the questionnaires in the researcher's presence, and the responses were analyzed.

The vocabulary-building activities chosen for primary investigation were based on the subject's needs. Most of the tasks were selected from the prescribed curriculum, "The SPINE Series Pupil's Book 5." The selected activities were simplified to suit the learners' current proficiency and understanding level in everyday vocabulary usage in the target language and to enrich their vocabulary. The researchers motivated the subjects before initiating an activity, as motivation prepares them to participate and lessen their anxiety levels actively. They learned effective learning tactics continuously while performing the activities. This helped them develop an acquaintance with vocabulary and English as a foreign language effortlessly $[10,23,24]$.

(1) Vocabulary Building Activities. Working with words: to motivate subjects to participate in vocabulary building activities working with words was introduced by choosing some simple primary words to be formed as compound words. The subjects were given a set of words like "table, board, cloth, week, chair, set, put," and so on to create possible forms of the compound words [12]. Most of the students found the activity interesting to learn new words from the given primary words.

Word challenge: word challenge was introduced with letters in puzzle word squares to be identified and written to create meaning full professions. The researchers presented a word puzzle from the curriculum. They asked the subjects to guess the words related to the names of professions, for example, "accountant, zmtailorxr, rteacherou, qurzlawyer, actorxyizv, docotxyizy, rnfdwaiter" [12]. The subjects tried to identify the hidden names from the word squares puzzle to produce meaningful professions. All the subjects participated in the word challenge, and it is a game of much fun for secondary school students to enrich vocabulary building.

Brainstorming: brainstorming was introduced to make the subjects think creatively and link images that they can hear, see, and smell in their surroundings to build their vocabulary. It is a process in which subjects strive to stimulate and generate ideas creatively, applying critical thinking skills [10]. The subjects were asked to brainstorm their views on "walking to Omdurman Suk or any Suk and list things they heard, saw, and smelled" [12]. All the subjects participated in brainstorming and showed interest in writing the right words related to their experience at "Omdurman Suk" (supermarket). This activity helped the subjects to think in minute details about the list of words like sounds, sights, and smells that were pleasant to them.

Spine challenge: spine challenge, a vocabulary game, was introduced with some jumbled words given as pieces to identify and rearrange in a sequential order to form meaning full words. The researchers presented the disorderly words related to the post office like "aprpe, ssaddre, evleenpo, kni, npe, atde, msatp" [12] to the subjects and asked them to arrange into meaningful words. The subjects need to guess the correct word from the given disorderly list to produce meaningful words. This game can be adapted to teach any vocabulary item to make it enjoyable to secondary school students. 
Crossword puzzle: crossword puzzle was introduced with arranged empty boxes in both horizontal and vertical order to be filled in a chronological order to form meaning full words. The researchers presented a crossword puzzle to the subjects and asked them to find meaningful words from the clues provided under the puzzle. The given clues are "one of the largest tribes in Western Sudan, a building for performing plays, the way people are entertained, one of the seasons, the opposite of no, skilled workers who repair machines" [12]. The subjects tried to guess appropriate or nearly close words from the clues in their responses. All the subjects participated in the crossword puzzle and enjoyed the activity.

Word game: word game was introduced to develop imagination and vocabulary building. An entertaining word game was created using five by five squares to polish our subject's vocabulary. This game can be adapted to teach vocabulary in an exciting method to make meaningful full words. The researchers prepared a board, and word game squares were drawn for the subjects to place 25 letters they hear anywhere randomly on the board as "oiofp, aniol, rtnig, bokef, setgo." After setting those 25 letters, the subjects were asked to count some meaningful words from their letters grid horizontally and vertically and cross each grid with a correct significant word. The subjects crossed the grid, and the responses were given. This language game can be adapted to teach any vocabulary item, and it is a great way to motivate learners of secondary schools.

\section{Results}

5.1. Findings of Preliminary Observation. In the present research study, one of the researchers works as an English instructor at Ahfad University Khartoum state. The researchers initially began interaction with the subjects in her first introductory class to identify why students should study literature and what genre they like to enrich their vocabulary. The researchers further explored how school facilities affect the teaching of literature and the role of Sudanese EFL secondary school students. The subjects were initially hesitant to speak; later, the researchers motivated them and took a few meetings to get their honest views. All the sixty-five subjects were observed from time to time to get authentic information for the further research study. According to the researcher's observation and informal talks, after one month, it was found that the girls were more interested in reading, writing, and vocabulary acquisition activities. Boys were frustrated and more complaining about their teachers, curriculum, school, and environment.

5.2. Findings of Primary Investigation Stage II. Primary investigation stage II presents the discussion, analysis, and interpretation of the data collected through the questionnaires from seventy-nine respondents of Ahfad Secondary School. After the researchers had distributed the questionnaire to the participants, both students and teachers constructed the required tables for collected data. This step consisted of transformation of the qualitative (nominal) variables (agree, disagree, neutral) to quantitative variables $(1,2,3)$, respectively. The collected data has been computerized and analyzed by Statistical Package for the Social Sciences (SPSS). The statements in the questionnaire have been analyzed in terms of frequencies and percentages, and the mean value calculated the responses of the four sections of questionnaire statements.

\subsection{Findings of Questionnaire}

5.3.1. Students and Teachers Opinion. Table 1 discusses the summary of responses to teacher factors from the student's and teacher's opinion: the subjects were given five statements on their opinion on the usage of literature in teaching vocabulary acquisition. The statistical results in Table 1 above show that all five statements are significant, but statements two and five reveal high indicators about literature teaching and vocabulary building from students' opinions. It is clear that the majority of teachers $80 \%$ use various teaching methods and aid in helping the subjects acquire vocabulary. Moreover, a majority of $81 \%$ of teachers help students inculcate literature to develop vocabulary. In contrast, to the teacher's opinion, it is clear that all statements are significant. However, statements one and two reveal high indicators that the majority of $79 \%$ of teachers lack adequate training in teaching literature and vocabulary acquisition to the secondary school students of Ahfad. Teachers use various teaching methods to teach literature in vocabulary acquisition agreed by only $64 \%$ of teachers. It is recommended that all teachers receive training through workshops to facilitate the exchange of experiences amongst teachers. Likewise, teachers should help students value their learning outcomes through literature for vocabulary acquisition. They should train the students to state, write, and analyze their opinions, discuss their ideas, and share their experiences through various pieces of reading. If some teachers lack adequate training in imparting literature, this does not affect the teaching process of the English language at secondary schools in Khartoum. Thus, the main reason for the recent deterioration in English language standards in the secondary schools of Khartoum is the absence of relevant literature from the curriculum.

Table 2 discusses the summary of responses to school facilities from the students' and teachers' opinions: the subjects were given three statements on the provision of school facilities in the usage of literature in vocabulary acquisition. It was observed that both students and teachers in statement one have agreed that lack of school facilities has positively affected the teaching and learning of vocabulary acquisition in secondary schools. It indicates that the school facilities were responsible for hindering the overall development of language teaching through literature in the secondary school of Ahfad. Statement two suggests that the inadequate quality of instructional materials has led to the poor implementation of the curriculum. It is evident that lack of quality instruction materials hinders low performance and has affected the teaching of literature and vocabulary acquisition at Ahfad Secondary School Khartoum. 
TABLE 1: Summary of subjects' responses to teacher factor.

\begin{tabular}{|c|c|c|c|c|c|c|}
\hline \multirow[b]{2}{*}{ Statements } & \multicolumn{3}{|c|}{ Students responses } & \multicolumn{3}{|c|}{ Teachers responses } \\
\hline & $\begin{array}{l}\text { Agree } \\
(\%)\end{array}$ & $\begin{array}{l}\text { Disagree } \\
\quad(\%)\end{array}$ & $\begin{array}{l}\text { Neutral } \\
(\%)\end{array}$ & $\begin{array}{l}\text { Agree } \\
(\%)\end{array}$ & $\begin{array}{l}\text { Disagree } \\
(\%)\end{array}$ & $\begin{array}{l}\text { Neutral } \\
(\%)\end{array}$ \\
\hline $\begin{array}{l}\text { (1) Some teachers lack adequate training in teaching literature and } \\
\text { vocabulary building. }\end{array}$ & 27 & 64 & 9 & 79 & 0 & 21 \\
\hline $\begin{array}{l}\text { (2) Teachers use various teaching methods and teaching aids } \\
\text { depending on the literature and vocabulary. }\end{array}$ & 80 & 8 & 12 & 64 & 7 & 29 \\
\hline $\begin{array}{l}\text { (3) Teachers conduct continuous assessment exams to test students. } \\
\text { progress in vocabulary. }\end{array}$ & 72 & 14 & 14 & 57 & 14 & 29 \\
\hline $\begin{array}{l}\text { (4) Teachers help in leading an effective and fruitful discussion } \\
\text { about a literary text. }\end{array}$ & 61 & 28 & 11 & 29 & 57 & $14 \%$ \\
\hline $\begin{array}{l}\text { (5) Teachers help students in valuing learning about literature and } \\
\text { vocabulary. }\end{array}$ & 81 & 8 & 11 & 58 & 21 & $21 \%$ \\
\hline
\end{tabular}

TABLE 2: Summary of subjects' responses to school facilities.

\begin{tabular}{|c|c|c|c|c|c|c|}
\hline \multirow[b]{2}{*}{ Statements } & \multicolumn{3}{|c|}{ Students responses } & \multicolumn{3}{|c|}{ Teachers responses } \\
\hline & $\begin{array}{c}\text { Agree } \\
(\%)\end{array}$ & $\begin{array}{c}\text { Disagree } \\
(\%)\end{array}$ & $\begin{array}{c}\text { Neutral } \\
(\%)\end{array}$ & $\begin{array}{c}\text { Agree } \\
(\%)\end{array}$ & $\begin{array}{c}\text { Disagree } \\
(\%)\end{array}$ & $\begin{array}{c}\text { Neutral } \\
(\%)\end{array}$ \\
\hline $\begin{array}{l}\text { (1) Lack of school facilities has affected learning and teaching of } \\
\text { literature process in the school. }\end{array}$ & 68 & 21 & 11 & 50 & 43 & 7 \\
\hline $\begin{array}{l}\text { (2) Inadequate quality of instructional materials has led to the poor } \\
\text { implementation of the curriculum. }\end{array}$ & 51 & 29 & 20 & 57 & 36 & 7 \\
\hline $\begin{array}{l}\text { (3) Physical facilities e.g., library, literature books, modern } \\
\text { (classrooms, desks, seats) has affected the teaching of literature and } \\
\text { vocabulary building. }\end{array}$ & 51 & 14 & 35 & 53 & 29 & 18 \\
\hline
\end{tabular}

TABLE 3: Summary of subjects' responses to students' interests.

\begin{tabular}{|c|c|c|c|c|c|c|}
\hline \multirow[b]{2}{*}{ Statements } & \multicolumn{3}{|c|}{ Students responses } & \multicolumn{3}{|c|}{ Teachers responses } \\
\hline & $\begin{array}{l}\text { Agree } \\
(\%)\end{array}$ & $\begin{array}{l}\text { Disagree } \\
(\%)\end{array}$ & $\begin{array}{l}\text { Neutral } \\
(\%)\end{array}$ & $\begin{array}{l}\text { Agree } \\
(\%)\end{array}$ & $\begin{array}{l}\text { Disagree } \\
(\%)\end{array}$ & $\begin{array}{l}\text { Neutral } \\
(\%)\end{array}$ \\
\hline $\begin{array}{l}\text { (1) Students like reading literature books that offer good motivation } \\
\text { for learning new vocabulary. }\end{array}$ & 90 & 5 & 5 & 57 & 29 & 14 \\
\hline $\begin{array}{l}\text { (2) There is a cordial relationship between literature and vocabulary } \\
\text { building. }\end{array}$ & 66 & 25 & 9 & 50 & 40 & 10 \\
\hline (3) Students read extra literature books outside the classroom. & 88 & 11 & 1 & 72 & 21 & 7 \\
\hline (4) Students enjoy reading the romantic genre of literature. & 74 & 18 & 8 & 79 & 21 & 0 \\
\hline (5) Our school gives us books as rewards and reinforcement. & 29 & 15 & 56 & 50 & 43 & 7 \\
\hline
\end{tabular}

However, statement three shows that low indicators of using literature books and physical facilities have affected subjects. A majority of $53 \%$ of teachers have expressed no excellent literature books, and the unavailability of modern (classrooms, desks, seats) has also affected literature teaching in vocabulary acquisition. The usage of outdated instructional materials will naturally hinder the learning process of the subjects. Therefore, teaching literature should be obligatory but not optional to understand its essential role in vocabulary acquisition and improvement.

Table 3 discusses the summary of responses to students' interests from the students and teacher's opinions: the subjects were given five statements on their self-interest to improve their vocabulary acquisition. Here, the researchers mainly focused on the subject's interest in reading literature and the time spent outside the classroom referring to academic books, articles, storybooks, novels, and magazines. It was observed that the majority of the responses were positive, and the subjects tried to upgrade their language skills and vocabulary with the help of articles and books. Statement one reveals a high indicator that $90 \%$ of students agreed that they liked they were reading literature to enrich their vocabulary. In contrast, to teacher's opinion, statement one indicates that a majority of only $57 \%$ of teachers agreed that subjects like reading literature books to improve their vocabulary. Therefore, to inculcate a habit of reading literature among subjects, the researchers focused on implementing a couple of reading sections like "A Success Story," "Sudanese Hospitality," "The Life of a Mechanic," "Women and Food Technology," "The Fight Against Germs," "Endangered Species," "Satellites and Computers," "William Shakespeare," and "Hellen Keller" [12] to make subjects read, analyze, and interpret the meaning, thereby refining and enhancing their communicative ability in the English 
TABLE 4: Summary of subjects' responses to actions taken to improve the curriculum.

\begin{tabular}{|c|c|c|c|c|c|c|}
\hline \multirow[b]{2}{*}{ Statements } & \multicolumn{3}{|c|}{ Students responses } & \multicolumn{3}{|c|}{ Teachers responses } \\
\hline & $\begin{array}{l}\text { Agree } \\
(\%)\end{array}$ & $\begin{array}{l}\text { Disagree } \\
\quad(\%)\end{array}$ & $\begin{array}{l}\text { Neutral } \\
(\%)\end{array}$ & $\begin{array}{l}\text { Agree } \\
(\%)\end{array}$ & $\begin{array}{l}\text { Disagree } \\
\quad(\%)\end{array}$ & $\begin{array}{c}\text { Neutral } \\
(\%)\end{array}$ \\
\hline $\begin{array}{l}\text { (1) Teaching interesting literature books, romantic and } \\
\text { detective books }\end{array}$ & 50 & 22 & 28 & 70 & 12 & 18 \\
\hline $\begin{array}{l}\text { (2) Motivate students to read literature to help in increasing } \\
\text { vocabulary }\end{array}$ & 65 & 23 & 12 & 77 & 13 & 10 \\
\hline $\begin{array}{l}\text { (3) Provide adequate and quality teaching and learning } \\
\text { resources }\end{array}$ & 68 & 23 & 9 & 80 & 11 & 9 \\
\hline $\begin{array}{l}\text { (4) More involvement of all school stakeholders in decision- } \\
\text { making }\end{array}$ & 52 & 32 & 16 & 60 & 30 & 10 \\
\hline
\end{tabular}

language with regard to clarity, range, comprehension, and pronunciation, as well as stating, recording, describing, and telling.

Statement three indicates that students enjoy reading extra literature books outside the classroom agreed by a majority of $88 \%$ of subjects. The teachers should make the students exhibit a practical and efficient approach to learning the reading skills necessary for succeeding in course content. The teachers were keen on arranging books as rewards and reinforcement to the subjects. The teachers wanted to have all kinds of books available in a library or a reading room to subjects from school facilities. Statement two was well supported by students and teachers that there is a cordial relationship between literature and vocabulary building. Statement four indicates that students enjoy reading the romantic genre of literature. $74 \%$ of the students enjoy reading the romantic genre of literature. Therefore, the teachers decided to involve students choosing books of "William Shakespeare's" romantic comedies from school facilities. The teachers should support the students in quality teaching and learning. They should make the students explain, justify, and interpret their opinions, discuss their ideas, and share their experiences through various reading pieces. Statement five states that giving rewards can be more encouraging to involve the subjects creatively agreed by $29 \%$ of subjects. The statistical results in Table 3 clearly show that most students enjoy reading literature books that offer good motivation to enrich vocabulary. From the above discussion, it is clear that teaching literature through "The SPINE Series Pupil's Book 5" provides a majority of subjects with accurate, authentic vocabulary through activities and familiarizes them with Sudanese culture and environment in EFL.

Table 4 discusses the subject's responses to actions taken to improve the curriculum from the students' and teachers' opinions: the subjects were given four statements. Statements two and three reveal high indicators of the most effective actions that could be taken to improve vocabulary acquisition in secondary schools from both students' and teachers' opinions. Here, the researchers mainly focused on the subject's interest in reading literature, the kind of exposure the subjects get by reading, motivating them to read books of all genres to learn new words to enrich their vocabulary. From statement two, the researchers checked subjects' interest in academic books, articles, storybooks, and novels at school, library, and home. It was observed that most of the responses were positive, and the subjects tried to upgrade their language skills and vocabulary with the help of articles and books. The statistical results in statement two from the teacher's opinion clearly show that motivating students to read literature helps in enriching their vocabulary. A majority of teachers and students agreed.

Statement three indicates providing good and quality teaching and learning resources. Introducing effective teaching methods and learner-friendly strategies can make the subjects achieve good proficiency in vocabulary acquisition regardless of heterogeneity in their classrooms. From the above-discussed responses, the researchers implemented vocabulary-building activities like "working with words, word challenge, brainstorming, spine challenge, crossword puzzle, and word game" from the curriculum [12] to check the subject's proficiency in vocabulary acquisition. Furthermore, providing adequate teaching and learning resources would benefit secondary school students. From the above-discussed information, involvement of all school stakeholders in decision making is needed to support the learning of literature for vocabulary acquisition and choose the excellent literature book such as "Things Fall Apart" [13], "Treasure Island" [25], or "The Hound of Baskervilles" [26] as part of the secondary school curriculum at Ahfad.

5.3.2. Potential Benefits of Using Literature in Vocabulary Building. There are many benefits of using literature in the classroom. It can generate opportunities for individual expression and learners' lexical and grammatical knowledge strengths. The literary texts in the language classroom can be a potentially powerful educational tool. "A teacher can help children build vocabulary by stretching words out, saying them slowly enough, so that children can hear their component sounds. In other words, starting the phrase will give children plenty of time to develop and practice this skill on their own" [22]. This leads to how children build vocabularies and their meanings in novel reading. Reading teaches better pronunciation, encourages fluent and expressive speaking, discovers new words or vocabularies and definitions, and understands the text or passage being read. "Reading is not just a linguistic exercise, but it involves getting meaning out of a text for some purpose" [27]. In practice, teaching vocabulary in the EFL classroom is not that easy but rather supplementing vocabulary knowledge 
through reading is more enjoyable and motivating for students.

It was observed that most subjects were able to work on the primary words and form them as instructed compound words. The subjects were given a set of words like "table, board, cloth, week, chair, set, put, ache, ash, ball, foot, head," and the responses were collected as "timetable, blackboard, tablecloth, weekend, armchair, setback, output, backache, ashtray, football, headteacher" [12]. The subjects tried to create possible forms of the compound words and enjoyed learning new vocabulary through working with words activity.

It was observed that subjects were able to construct meaning full professions from the word challenge puzzle, for example, "accountant, zmtailorxr, rteacherou, qurzlawyer, actorxyizv, docotxyizy, rnfdwaiter" [12]. They searched the word square puzzle in a horizontal and vertical order to find the hidden names of professions "for example, teacher, accountant, tailor, lawyer, actor, doctor, and waiter." All the subjects participated in word challenge puzzle to enrich their vocabulary building.

It was observed that subjects could brainstorm and link images in their surroundings to enrich their vocabulary. The subjects presented their ideas on "walking to Omdurman Suk" or other "suk" [12] by listing things they heard, saw, and smelled at "suk." All the subjects showed interest in writing the right words related to their experience at "Omdurman Suk" (supermarket). This activity helped the subjects think in minute details about the list of words they heard like noises, adaan from the nearby mosque (call for prayer), beep sound of vehicles, hawkers selling fruits and vegetables. The subjects wrote that they saw cars, busses, bicycles, and many people walking on narrow crowded streets of Omdurman Suk (supermarket). They smelled the fish and seafood, meat, and food prepared at the restaurants. A few subjects presented their opinion that the adaan sound from the mosque (call for prayer) and food smell from the restaurants were pleasant, and the fish, seafood smell, noises, and vehicle sound were unpleasant.

It was observed that subjects could guess the right words to identify and rearrange the jumbled words in a sequential order to form meaning full words in spine challenges. The subjects guessed words related to post office, "for example, paper, address, envelope, ink, pen, date, stamp.” Most subjects enjoyed the spine challenge, and this vocabulary item can be adopted to teach particular meanings to make it enjoyable to secondary school students.

It was observed that subjects could guess appropriate words from the clues provided in the given crossword puzzle to form meaning full words. The subjects thought words like "Bagara for one of the largest tribes in Western Sudan, theatre for a building for performing plays, entertainment or entertaining for the way people are entertained, summer or winter for one of the seasons, yes for the opposite of no, mechanic for skilled workers who repair machines" as their responses. All the subjects enjoyed the crossword puzzle activity.

It was observed that each subject placed 25 letters they heard anywhere on the board squares provided by the researchers. After identifying those 25 letters, the subjects searched for meaningful words they got from the letters grid both horizontally and vertically and crossed each grid with a correct word. The subjects crossed the grid, and the responses given were "on, in, into, so, son, no, set, go, dog, fit, an toe" [12]. This language game creates enthusiasm and motivates learners individually or in pairs to create their list of meaningful words.

\section{Discussion}

6.1. The Four Basic Aspects Affecting the EFL Secondary School Learners of Ahfad. The questionnaire results from students and teachers' opinions indicate that the most critical aspects affecting the use of literature to enrich vocabulary acquisition in secondary schools of Khartoum are students' interest, teacher factor, school facilities, and the curriculum. In addition, the results show a high and low variation affecting these four factors from teachers' and students' opinions. There was a clear implication that though some students do not show interest in improving their English language or vocabulary, a lot can be done to improve student's vocabulary by enhancing the effectiveness of curriculum, school's facilities, and with the expertise of the available teachers, with a good collection of literature books. Effective teachers appear to be effective with students of all abilities. If teachers are effective, and schools have good facilities, students are more motivated and benefit more.

Figure 1 shows the summary of the teacher factors. The students' responses to the teacher factor have a higher average of 64.2 than the teachers' responses with 57.4. Moreover, the students disagreed with the statements with an average of 24.4, which is higher than the teacher's responses with an average of 19.8. On the contrary, the students' responses remained neutral with an average of 11.4, which was significantly lower than the teachers' responses with an average of 22.8. The students' response to the teacher factor has a very low standard deviation of 1.62 compared to the teachers' responses of 5.65.

From the above-discussed average and standard deviation, the researchers noticed that most opinions go side by side. It was observed that a majority of teachers felt that the significant factors affecting the teaching of literature are teachers' qualification, experience, and techniques adopted in the classroom, and their background knowledge on literature (refer to Table 1).

Figure 2 shows the summary of school facilities. A majority of students agreed to the statements with an average of 56.67, higher than the teachers' responses with an average of 53.33. On the contrary, most teachers disagreed with the statements with a high average of 36.00 compared to the student disagreement with the school facilities with a low average of 22.00. Astonishingly, students scored neutral with a high average of 22.00 compared to the teachers' responses with a lower average of 10.67 . The figure above illustrates the standard deviation of the teacher's responses to school facilities, which are as low as 2.87 compared to the student's responses of 8.01 .

Physical learning environments in which formal learning occurs range from relatively modern, well-equipped 


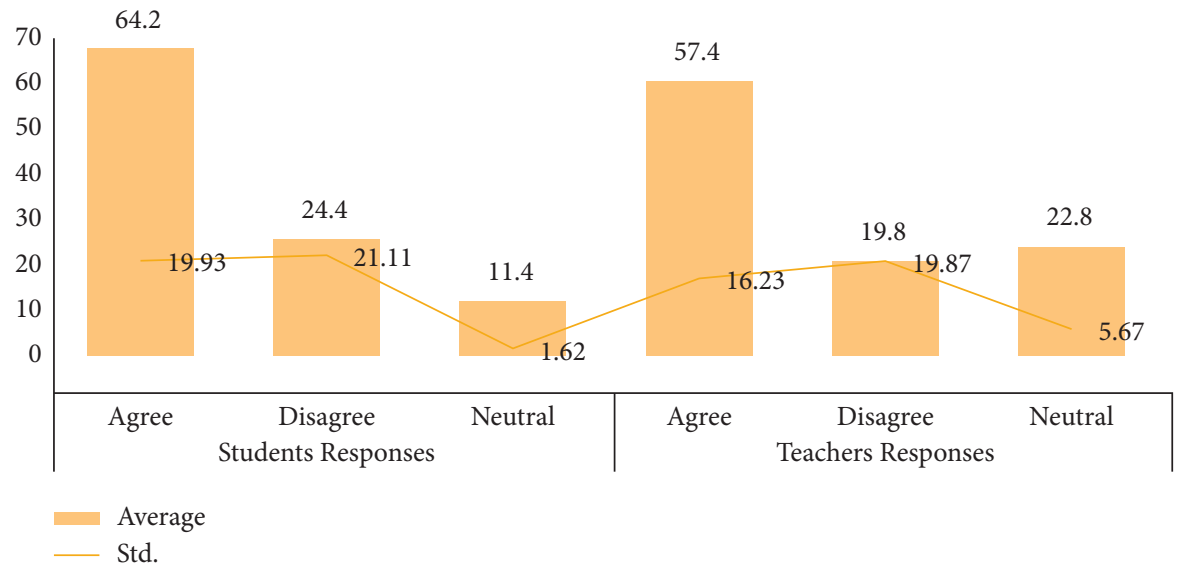

Figure 1: Summary of teacher factor aspect.

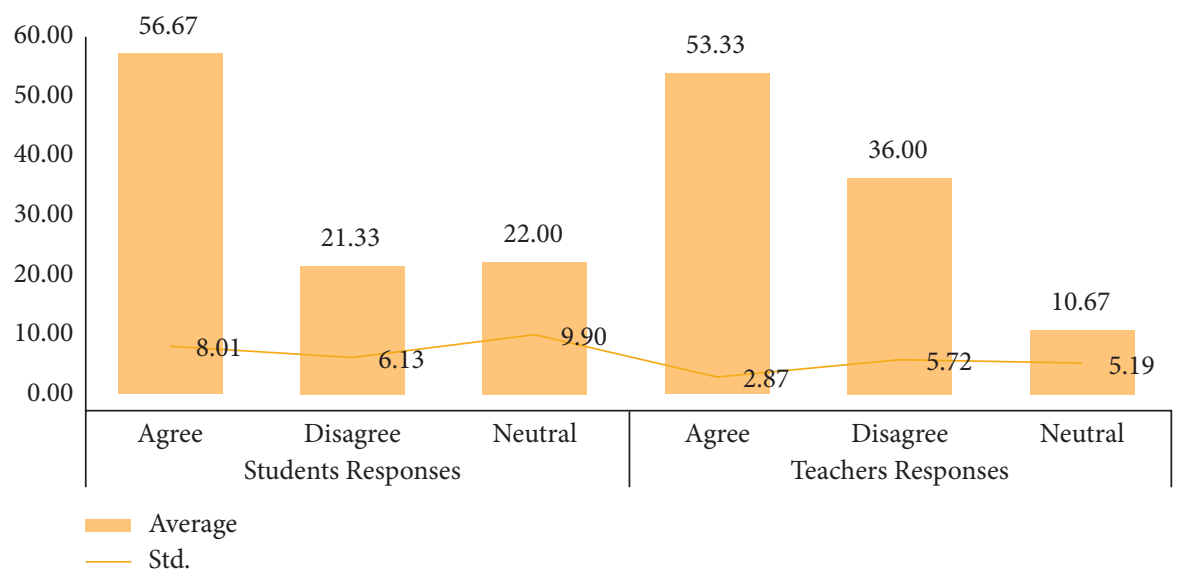

FIGURE 2: Summary of school facilities aspect.

buildings to open-air classrooms. It is tough to measure the effectiveness of the quality of the school facilities on learning directly. Factors such as on-site availability of library, suitable books of literature, teaching and learning materials, classroom maintenance, space, and furniture availability all impact the critical learning factors and time taken on a task.

Sudan is amongst the countries that pointedly expanded access to elementary education in the 1990s. For many new students, schools have often had to increase class size and student-teacher ratios to look and copy notes on boards and consequently understand the lesson. Classrooms, desks, and seats have been modernized.

One of the essential factors that affect learning English is the school library. Ahfad Secondary School has no library and books. The school library has been shown to impact students' achievement positively. As we all know, any school needs a library, because they support literacy and education. When students learn that the library has soccer yearbooks, novels, and periodicals, they may decide to spend some of their free or valuable time reading. The more students read, the faster their English will improve. This will help them in their studies and when they leave high school. The school library supports the students studies. A school library may also have books by local writers that will encourage students' interest and pride in the local area. Providing access to information, a school library allows students to develop the skills of searching for information on their own. This could help activate the learning approach and develop problem-solving. School learners who regularly search for information in books can improve both forms of work and reading skills. Libraries are also beneficial for teachers. Using the textbooks and other references in the library will help teachers prepare their lessons better. It may also encourage teachers to give students project work that asks them to go to the library and find out information. This will inspire learners to read, learn, and achieve better results and give them the confidence to start looking for information independently.

Figure 3 shows the summary of students' interests. Most students agreed to the statements with an average of 69.40, which is relatively higher than the teachers' responses with an average of 61.60. On the contrary, most teachers disagreed with the statements with a high average of 30.80 compared to the students' disagreement with the students' interest with a low average of 14.80. Surprisingly, students scored neutral with a high average of 15.80 compared to the teachers' responses with a lower average of 7.60. The figure 


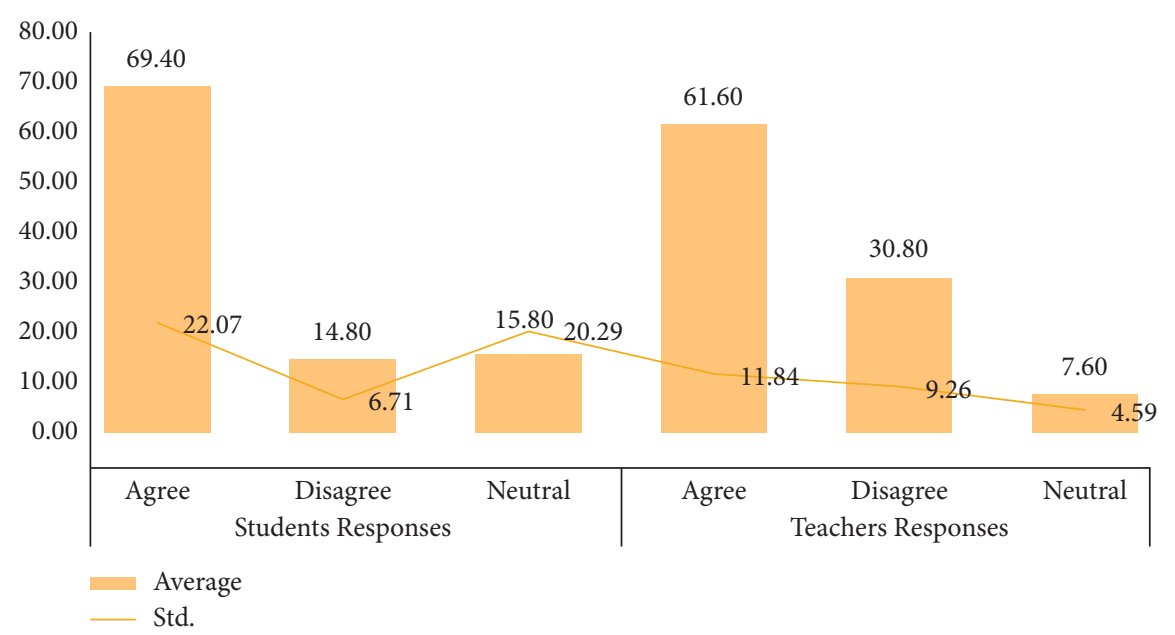

Figure 3: Summary of student's interest aspect.

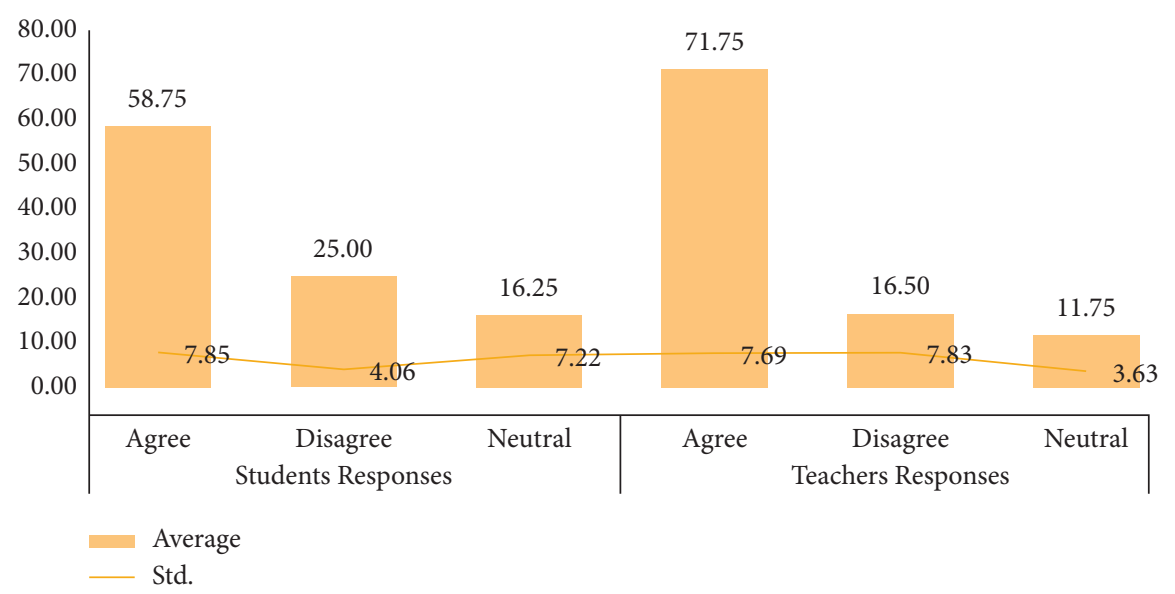

Figure 4: Summary of curriculum aspect.

above illustrates the standard deviation of the teachers' responses to students' interests, which is low at 4.59 compared to the students' responses of 6.71 .

Developing interest in secondary school students academically needs a lot of effort and creativity on the teachers' side. An English teacher must showcase a diversity of responsible roles as a curriculum designer, planner, mentor, facilitator, motivator, and language expert [10]. In literature class, an English teacher should first clearly and distinctively read the passage sections to make the students listen to the articulation of the sounds and words. The teacher should read each passage twice to make students understand the text using simple vocabulary, and after that, the students should be involved with in-class participation activities. After the second reading of the passage, the teacher should write the hard words and new words on the blackboard and explain to the learners the meanings.

After the teacher reads the passage, each student should be given a chance to read a small paragraph aloud. Furthermore, the teacher should assign students reading assignments beforehand instead of discussing the reading sections orally in the classroom. The teacher should discuss the lesson and recapitulate what learners have learned from the reading section through activities focusing on grammar, vocabulary, and pronunciation. Deci and Ryan point out that "feelings of competence and self-determination engendered by a reading task in reading affect the reader's intrinsic motivation for it" [28]. In addition, selection of the reading sections is crucial as Cope and Worthy emphasize that "authentic texts and choice in selecting reading materials are essential for fostering reading persistence in struggling secondary readers" [29, 30]. However, Collins, Ryan and Brewer, and Kumar affirm that choosing authentic materials has also improved reading interest and skill among these students [31-33]. Cameron and Pierce assert that "to create intrinsic motivation in students is enhanced through verbal praise and positive feedback, primarily when the task is well performed" [34]. So, intrinsically motivated readers persist in reading because of effective engagement with the text and their satisfaction from the task.

Figure 4 shows the summary of the curriculum aspect. It was observed that many students agreed to the statements with an average of 58.75, which is relatively lower than the 
teachers' responses with an average of 71.75 on curriculum issues. On the contrary, most of the teachers disagreed with the statements with a high average of 25.00 compared to the students' disagreement with the curriculum with a low average of 16.50. Surprisingly, students scored neutral with a high average of 16.25 compared to the teachers' responses, which have a lower average of 11.75 . The figure above describes the standard deviation of both the students' responses and the teachers' responses of the curriculum, which shows similar agreement of 7.85 and 7.69 , respectively.

From the above discussion, it was decided that the textbooks used for literature should be improved to a high standard to enhance and enrich the students' knowledge of the language, literature, and vocabulary. Introducing books with varieties of topics and rich vocabulary would interest students and motivate them, adding new vocabulary books especially for second-year secondary school students apart from the regular curriculum. We conclude that the literature books should be related to students' culture with suitable audio-visual aids to make teaching more fruitful. Continuous assessment, extra reading texts given as assignments, inculcating reading and writing habits by providing books and materials, and facilitating students to inculcate the spirit of writing compositions are the prior actions to be implemented to acquire the excellent habit of reading.

\section{Conclusion}

The main conclusion of the findings of this study is to ascertain the four basic aspects affecting the Sudanese EFL secondary school student's vocabulary acquisition. The first and the most affecting aspect is the student's interest. The analysis affirmed that it takes a lot of effort and imagination on the teachers' part to get secondary school EFL students interested in learning-secondly, the teacher factor is also a significant aspect. The analysis also showed that most teachers felt that teacher qualification, experience, classroom techniques, background knowledge of literature, cultural factors, and lack of trained teachers were the most critical factors affecting the teaching of literature. Thirdly, the curriculum aspect has a practical impact on developing students' vocabulary. The analyzed data leads us to conclude that literature books should be related to the student's culture with appropriate audio-visual aids to make teaching more effective. Finally, the school facilities aspect has the most negligible impact on learning and vocabulary acquisition. The data collected and analyzed from the questionnaire confirmed that the effect of school facilities on learning is difficult to measure directly, because several factors influence critical learning and the amount of time it takes to complete a task. In general, this study's findings can help improve the vocabulary-building process at Ahfad Secondary School Khartoum.

This study found that though Sudanese EFL secondary school learners have severe difficulties with vocabulary acquisition, it was analyzed through collected data that $69 \%$ of the subjects expressed their interest. While learning new vocabulary, the majority of $90 \%$ of subjects agreed. Moreover, according to the study, $88 \%$ of subjects read literature outside class. Using the teachers' responses as a guide, it was determined that the students enjoyed reading romantic literature. This is because literature and language learning are inextricably linked.

Finally, the conclusion confirms that the curriculum impacts EFL secondary school students' literature and vocabulary instruction. In addition, literature is used to help EFL students learn new vocabulary. As a result of this study, policymakers, educational reformers, and academic program directors will be more aware of what can be done to help Sudanese EFL students overcome difficulties, such as what the researchers mentioned earlier, expand their vocabulary, and improve the spirit of reading sections to achieve academic success.

\section{Recommendations for Further Studies}

The current study focused on the attitudes and perceptions of Sudanese EFL secondary school students toward learning literature to expand their vocabulary; thus, assuming that the findings are generalizable to the entire education system may be incorrect. Future research will add value by focusing on the tertiary levels, as experiences, needs, challenges, and priorities differ within and between subsectors. Future studies should also use better designs and larger sample sizes to generate more robust models for estimating learning literature to help them expand their vocabulary. As a result, the researchers make the following research suggestions for future study: the impact of imagery strategy on EFL learners' vocabulary learning and reinforcing academic vocabulary use in writing.

\section{The Limitation of the Study}

Although the study focused on the attitudes and perceptions of Sudanese EFL secondary school students and teachers of the English language toward learning literature to enrich their vocabulary, the findings may not provide an accurate picture of the entire education system because experiences, needs, challenges, and priorities differ across secondary levels.

\section{Data Availability}

The data that support the findings of this study are available from the corresponding author upon reasonable request.

\section{Conflicts of Interest}

The authors declare that there are no conflicts of interest.

\section{References}

[1] J. Bloemert, A. Paran, E. Jansen, and W. van de Grift, "Students' perspective on the benefits of EFL literature education," The Language Learning Journal, vol. 47, no. 3, pp. 371-384, 2019.

[2] M. Ajmal, T. Kumar, and A. H. Shah, "The application of literary text in language classroom: a pedagogical stylistics perspective," Asian EFL Journal, vol. 27, no. 4, pp. 384-402, 2020. 
[3] S. H. H. Barzani, R. S. Meena, and M. F. Ali, "Integration of literature in English language teaching: learners' attitudes and opinions," Canadian Journal of Language and Literature Studies, vol. 1, no. 1, pp. 27-43, 2021.

[4] K. A. J. Dweikat and G. Shbietah, "An investigation on approaches used by school teachers in teaching the literature components in EFL classrooms/English for Palestine case," Al-Quds Open University, vol. 2, no. 7, pp. 11-49, 2014.

[5] K. Herr, "The role of literature in secondary and post-secondary language instruction: disparity or unity?" Foreign Language Annals, vol. 15, no. 3, pp. 203-207, 1982.

[6] A. Paran, "The role of literature in instructed foreign language learning and teaching: an evidence-based survey," Language Teaching, vol. 41, no. 4, pp. 465-496, 2008.

[7] M. Ajmal and T. Kumar, "Using dialang in assessing foreign language proficiency: the interface between learning and assessment," Asian ESP Journal, vol. 16, no. 2.2, pp. 335-362, 2020.

[8] T. Kumar, "Assessing language need and proficiency of English graduates of Prince Sattam Bin Abdulaziz University for designing pre-placement training and workshops," Asian ESP Journal, vol. 16, no. 4, pp. 153-168, 2020.

[9] M. Reed and J. Levis, The Handbook of English Pronunciation, John Wiley \& Sons, Hoboken, NJ, USA, 2019.

[10] S. F. Jahara and A. H. Abdelrady, "English café: an initiative to encourage undergraduate learners of Al-Asyah Province to showcase their spoken proficiency in English," Journal of Ethnic and Cultural Studies, vol. 8, no. 3, 2021.

[11] I. Elsheikh, Evaluation of spine textbooks for teaching english in sudanese secondary schools, Ph.D. dissertation, University of Khartoum, Khartoum, Sudan, 2015.

[12] A. B. Al Faki, J. Ukele, S. Arbab, and T. Hadra, The Spine Series Pupil's Book, El Tarbia Printing Press, Khartoum North, Sudan, 1996.

[13] C. Achebe, Things Fall Apart, Anchor Books, New York, NY, USA, 1959.

[14] E. H. Hiebert and M. L. Kamil, Teaching and Learning Vocabulary: Bringing Research to Practice, Routledge, London, UK, 2005.

[15] D. E. Norton, The Effective Teaching of Language Arts, C.E. Merrill Publishing Company, Indianapolis, IN, USA, 1980.

[16] K. E. Stanovich, "Matthew effects in reading: some consequences of individual differences in the acquisition of literacy," Reading Research Quarterly, vol. 21, no. 4, pp. 360-407, 1986.

[17] S. L. Nist and C. Mohr, Improving Vocabulary Skills, Townsend Press, Berlin Township, NJ, USA, 2005.

[18] R. Diyanni, Literature: Reading Fiction, Poetry, Drama, and the Essay, McGraw-Hill, New York, NY, USA, 1990.

[19] G. A. Boyd, Linguistics in the Elementary School Itasca, Ill, F.E. Peacock, Itasca, IL, USA, 1976.

[20] T. Kumar, "Impact of motivation and group cohesion in EFL classrooms at Prince Sattam Bin Abdulaziz University, KSA," Asian EFL Journal, vol. 27, no. 4, pp. 116-131, 2020.

[21] S. F. Jahara and A. H. Abdelrady, "Pronunciation problems encountered by EFL learners: an empirical study," Arab World English Journal, vol. 12, no. 4, pp. 194-212, 2021.

[22] S. B. Neuman, "The role of knowledge in early literacy," Reading Research Quarterly, vol. 36, no. 4, pp. 468-475, 2011.

[23] M. Ajmal and T. Kumar, "Inculcating learners' listening motivation in English language teaching: a case study of British education and training system," Arab World English Journal (AWEJ), vol. 11, no. 4, pp. 409-425, 2021.
[24] T. Kumar, "'Desire to learn, learn to shine': idolizing motivation in enhancing speaking skill among L2 learners," Cypriot Journal of Educational Sciences, vol. 16, no. 1, pp. 411-422, 2021.

[25] R. Stevenson, Treasure Island, Kingfisher, New York, NY, USA, 2001.

[26] A. Doyle, The Hound of the Baskervilles: Another Adventure of Sherlock Holmes, Penguin Books, London, UK, 2001.

[27] C. Nuttall, Teaching Reading Skills: In a Foreign Language, Heinemann, London, UK, 2nd edition, 2005.

[28] E. L. Deci and R. Ryan, "Cognitive evaluation theory," in Intrinsic Motivation and Self-Determination in Human BehaviorSpringer, Boston, MA, USA, 1985.

[29] J. Worthy, "A matter of interest: literature that hooks reluctant readers and keeps them reading," Document Reproduction No.ED 354 506, ERIC, New Delhi, India, 1993.

[30] J. Deci and R. Ryan, "Cognitive evaluation theory," The Reading Teacher, vol. 50, no. 3, pp. 204-212, 1996.

[31] N. D. Collins, "Motivating low performing adolescent readers," Digest (ERIC Document Reproduction Service No. ED 396 265), ERIC, New Delhi, India, 1996.

[32] S. M. Ryan and B. Brewer, "Changing the English curriculum for at-risk high school learners," Journal of Reading, vol. 33, no. 4, pp. 270-273, 1990.

[33] T. Kumar, V. Nukapangu, and A. Hassan, "Effectiveness of code-switching in language classroom in India at primary level: a case of L2 teachers' perspectives," Pegem Journal of Education and Instruction, vol. 11, no. 4, pp. 379-385, 2021.

[34] J. Cameron and W. D. Pierce, "Reinforcement, reward, and intrinsic motivation: a meta-analysis," Review of Educational Research, vol. 64, no. 3, pp. 363-423, 1994. 